\title{
32
}

\section{Our Plastic Brain: Remembering and Forgetting Art}

Heather H. Yeung

In What Should We Do With Our Brain? Catherine Malabou exposes a necessary dialectic at the foundation of neuroplasticity, where the foundation of each identity is a kind of resilience [. . . ] a kind of contradictory construction, a synthesis of memory and forgetting, of the constitution and effacement of forms. ${ }^{1}$ We meet again the inextricable figures of Memory, Mnemosyne, and Forgetting, Lesmosyne, and an acknowledgement of the importance to human identity formation of both memory and forgetting. It is my intention in this piece to investigate the importance of memory and of forgetting to the manner in which artistic forms have developed, particularly in relation to poetry and music and to what Malabou calls the 'constitution and effacement of forms'. Our relation to artistic forms, we will discover, often runs in parallel to our memory-biases; many classical art forms foster memorialisation, and are prized, whereas innovative forms (or anti-forms), which encourage or investigate forgetting are more contentiously received, and often meet with critical resistance.

Just as conventional art forms lead to easy remembrance, forgetting is put to productive use in many contemporary art forms. And, through their evasion of the conventional formal principles which lead the work of traditional or formal artists to be committed with ease to memory, they open up an aesthetic field for the experience of the artwork as anti-memorial. This sort of innovative forgettingthrough-art is not only an important reaction to the last 500 years of formal obsession in Western artistic practice, but through looking at form's relationship with memory and forgetting, we discover a simple rationale for a lot of the negative critical reactions and popular aversions to some of the twentieth and twenty-first centuries' most interesting works of art.

Countless mythologies link memory to the arts, and perhaps most of all to the poetic and musical arts: the original three Boeotian muses were Melete (thought), Mneme (memory) and Aoide (song); all but two of Mnemosyne's nine daughters are associated with poetry and music; the apostrophic invocation of many Western poets and song-writers is addressed to the muses, daughters of memory. Already, if only through the lens of myth, we can link the formal operations of memory with those of poetry and music. The relationship of form to forgetting is the shadowy dialectic to this, and may be approached covertly, through an 
appreciation of the converse to the ways in which the basic formal elements of poetry and music relate to the operations of memory.

Although he perhaps takes too disaffected or technical a view of poetic power, Robert Pinsky writes 'poetry is, among other things, a technology for remembering. Like the written alphabet and the printing press and the digital computer, it is an invention to help and extend memory. ${ }^{2}$ It is indeed true that many of the formal aspects of poetry - rhythm, rhyme, repetition, appropriate metaphor, direction of address - also act as constructions which aid remembrance. And, since memory 'relies on the "placing" or contextualization of language', these formal aspects, sometimes alongside a narrative sequence, are keys to easy memorization. A direct link between poetic and musical forms and neural plasticity and memory comes in the way these formal aspects operate, as the sets of words or notes from which they are composed very rarely stray from sequences of two - eight, mimicking the average brain's working memory capacity which has not really altered in theory since George A. Miller's research in the 1950s, which set this capacity at $n=7 \pm 2$. Form is there to help us to not forget.

Let us consider first two of the most predominant English accentual-syllabic forms: the ballad and the sonnet. As a traditionally narrative poem, the ballad has a story which must be committed to memory and then performed poetically. The formal structure into which this story is fitted is quite an astringent one: verses of four lines, made up of stressed lines of, alternately, four and three feet, and an $a b c b$ or $a b a b$ rhyme-scheme. We can see this form at work in the oft-anthologised ballad of Sir Patrik Spens:

The king sits in Dunfermlin town, Drinking the bluid-red wine:

'O whar will I get guid sailor, To sail this ship of mine?'

Up and spak an eldern knicht, Sat at the king's richt knee:

'Sir Patrick Spens is the best sailor That sails upon the sea'. ${ }^{3}$

This all fits in very neatly with Miller's law.

So, too, does the sonnet form, where the standard total of 14 lines is split into sections of either eight-six, four-four-four-two, or eight-four-two. The rhyme scheme of the Shakespearean (or 'English') sonnet follows this numerical patterning, as sections are rhymed $a b a b c d c d$ efef $g g$. These lines are comprised of five iambic feet apiece. We can see this form at work in Michael Drayton's sonnet 'Farewell to Love':

Since there's no help, come, let us kiss and part;

Nay, I have done, you get no more of me, And I am glad, yea glad with all my heart

That thus so cleanly I myself can free. 
Shake hands forever, cancel all our vows, And when we meet at any time again, Be it not seen in either of our brows That we one jot of former love retain.

Now at the last gasp of love's latest breath, When, his pulse failing, passion speechless lies, When faith is kneeling by his bed of death, And innocence is closing up his eyes;

Now if thou wouldst, when all have given him over, From death to life thou mightst him yet recover. ${ }^{4}$

Further afield, the traditional poetic line of the ancient Greeks, the dactylic hexameter (six stressed feet with possible internal variations of stress and caesura placement), also fits into Miller's law. As do the most common French poetic lines (feet are counted not by stress but syllable): the octosyllable (eight), decasyllable (ten), and alexandrine (12). The decasyllable is often broken down by a caesura into groups of five-five, four-six, or six-four, and the alexandrine, more famously, into hemstitches (groups of six syllables apiece).

In the various forms of Western Classical and Folk music, too, the most common time-signatures range from alla breve ( $2 / 2$, or two minim beats to a bar) and common time $(4 / 4$, or four crotchet beats to a bar), to duple time $(6 / 8$, or six quaver beats to a bar). It is very rare in conventional forms that the number of beats per bar go above twelve, particularly if there is no split in the stress (for instance, a bar marked 12/8 will often be divided into subsections of three quavers apiece, so each bar is effectively divided into four sub-bars of $3 / 8$ ).

As the piece of music grows out form these basic structures, like the poem, the larger form also takes on logical numerical divisions. Each bar of music will be built to comprise a musical phrase, which we often see to be made up of four or eight bars. The phrasal divisions of any folk tune illustrate these divisions well, or the theme of W. A. Mozart's 'Ah je vous dirais Maman', more commonly known in Anglophone countries as the nursery rhyme 'Twinkle Twinkle Little Star'. The Classical 'sonata' or 'first movement' form takes on a tripartite structure of 'exposition' (the melodic themes, usually two, are established), 'development' (the melodies are elaborated and contrasted) and 'recapitulation' (the melodic themes are resolved, and played again). On top of this, symphonic forms rarely have more than four movements.

Famously, J. S. Bach's Art of Fugue is no more than a series of developments of a slow four-bar phrase, or 'subject', in common time. Similar to this, the ancient Celtic piobaireachd form develops a short, slow, theme (the 'ground' or 'ular') by adding and subdividing note and harmony elements to create a series of variations. The ground itself will often have either a primary (two two-bar phrases), secondary (two one-bar phrases combined with two two-bar phrases) or tertiary (three two-bar phrases), form.

All of this formal construction and play aids memory through familiarity and repetition as well as through numerical breakdown. Form, indeed, breeds a sense 
of easy familiarity - who can really say, having read Shakespeare's sonnets, or played Haydn's piano sonatas, that they can only enjoy and remember fully one of the many works? For many, familiarity with a given structure, coupled with the ease of remembering its main parts (lines, or phrases), leads to a sense of comfort in form and a dislike from any divergence from this sense of familiarity in the artistic form at hand. In this frame of mind, form opposes a negative sense of randomness and disorder and a reluctance to engage with a work which rejects the expectation of and comfort in established formal structures.

The frisson of unknowability's foundations in forgetting (or fear of forgetting) which can be seen in the avant-garde art work, leads to the foregrounding of forgetting rather than remembering, and taps directly into the formal techniques of erasure, dispersal, and effacement of what we have come to recognize as the 'conventional' space of the poem on the page. Could it be that it is through their un-rememberability that contemporary avant-garde and digital works in music, poetry and the plastic arts, have sparked so strong and ongoing a critical debate and divide? How do we engage effectively and affectively with avant-garde, conceptual or digital poetic works which use techniques such as erasure, distortion, excessive repetition and blank space in order to work against memory? Could it be that the critical resistance to many avant-garde poetics lies in the fact that they work against memory at a formal and textual level and is it thus that forgetting forms the basis for the ascription of the label 'difficult' to more conventional poetic works that also work towards forgetting?

In a world where so much value is placed on memory and identity-formation through remembrance, the work of art which actively turns away from being remembered, whose poetic force rises from its embrace of its very forgettability, will necessarily often be rejected out of hand as lacking in value, consigned to dry academic analyses which pride themselves on countering the difficulty of the work with a theoretical prose just as impenetrable, or to coterie circles of practitioners who are open to these changing forms and media. There is an unfounded fear that, in forgetting, a lack of 'self' occurs. Thence the aversions to and ridicules of a-formal or avant-garde works of art, that are still promoted in many circles. . . But our brain operates both to constitute and also to efface forms. This oscillation is an important element of neuroplasticity. It follows that we should seek also to engage with artistic works which, although they may be less 'comfortable', or less 'rememberable', try to efface rather than to constitute forms, cultivating our own ars oblivionalis alongside the ars memoriae.

\section{Notes}

1. Malabou, What Should We Do With Our Brain?, 77, trans. Sebastian Rand (Fordham University Press, 2008).

2. Robert Pinsky, 'Poetry and American Memory', Atlantic Monthly 284(4) (1999), 60.

3. Anon, from 'Sir Patrick Spens', in A Book of Narrative Verse, ed. V. H. Collins (Oxford: Oxford University Press, 1931), 39.

4. Michael Drayton, Sonnet 61, in The Norton Anthology of Literature vol. 1 8th ed. (New York, W. W. Norton and Co., 2006), 1000. 